\title{
Costing model for neonatal screening and diagnosis of haemoglobinopathies
}

\author{
E K Cronin, C Normand, J S Henthorn, M Hickman, S C Davies
}

\begin{abstract}
Aim-To compare the costs and cost effectiveness of universal and targeted screening for the haemoglobinopathies; to compare the cost of two laboratory methods; and to estimate the cost effectiveness of programmes at different levels of prevalence and mix of haemoglobinopathy traits.

Methods-A retrospective review of laboratory and follow up records to establish workload and costs, and estimation of costs in a range of circumstances was made in a haematology department and sickle cell and thalassaemia centre, providing antenatal and neonatal screening programmes in Inner London. The costs for 47948 babies, screened during 1994, of whom 25 had clinically significant haemoglobinopathies and 704 had haemoglobinopathy traits, were retrospectively assessed.
\end{abstract}

Results-The average cost per baby tested (isoelectric focusing and high power liquid chromatography) was $£ 3.51 / £ 3.83$ respectively; the cost per case of sickle cell disease identified (IEF/HPLC) was $£ 6738 /$ $£ 7355$; the cost per trait identified (IEF/ HPLC) was $£ 234 / £ 255$; the cost per extra case of SCD and trait identified by universal programme varied.

Conclusions-IEF and HPLC are very similar in terms of average cost per test. At 16 traits/1000 and $0.5 \mathrm{SCD} / 1000$ there was no significant identification cost difference between universal and targeted programmes. Below this prevalence, a targeted programme is cheaper but likely to miss cases of SCD. If targeted programmes were 90-99\% effective, universal programmes would cease to be good value except at very high prevalence. Greater use of prenatal diagnosis, resulting in termination, and therefore fewer affected births, reduces the cost effectiveness of universal screening. Screening services should aim to cover a screened population which will generate a workload over 25000 births a year, and preferably over 40000 . (Arch Dis Child Fetal Neonatal Ed 1998;79:F161-F167)

Keywords: screening; haemoglobinopathies; cost effectiveness; workload
The costs of screening and diagnosis of haemoglobinopathies in newborns reported here are for a region where the prevalence is relatively high, but the model presented allows costs to be quantified for both targeted and universal screening in areas of differing prevalence. It is intended that this analysis will inform commissioning decisions on appropriate levels of screening for different health districts and supplement existing guidance. ${ }^{1}$ These decisions should depend on the proportions of the population who carry haemoglobinopathy traits, which are related to the concentration of specific ethnic populations (African, Caribbean, Mediterranean, Asian, and those from the Far East and Middle East) and costs of selection, screening, and follow up. $^{2}$

Two recent North American studies have examined the cost effectiveness of neonatal haemoglobinopathy screening. Tsevat et al ${ }^{3}$ concluded that screening black populations in the USA was very worthwhile, but for nonblack populations the cost was high for each case found and life extended. This study has been widely criticised for comparing screening in black and non-black populations rather than targeted and universal screening; for failing to consider the extra costs and reduced effectiveness resulting from selection; and for failing to recognise efficiencies inherent in universal screening. ${ }^{4-7}$

Sprinkle $e t a l^{6}$ looked at prevalence and costs of screening in individual States and concluded that universal screening could be provided at socially acceptable costs in demographically arranged diverse States, with cooperation on screening between some States. Their results indicated the cost effectiveness of universal screening in US populations where $5 \%$ of births were of African-American origin.

A particular problem inherent in screening only high risk groups is that some individuals belonging to these groups may be difficult to identify. Commissioners of screening programmes must consider difficulties in selection which may result in higher costs. They are also likely to make programmes less effective in identifying all neonates at risk for haemoglobinopathy, and risk litigation when those at risk are not selected for screening(Abstracts presented to National Neonatal Screening Symposia in 1992 and 1993 by P A Lane). ${ }^{45-14}$ The Standing Medical Advisory Committee report ${ }^{1}$ 


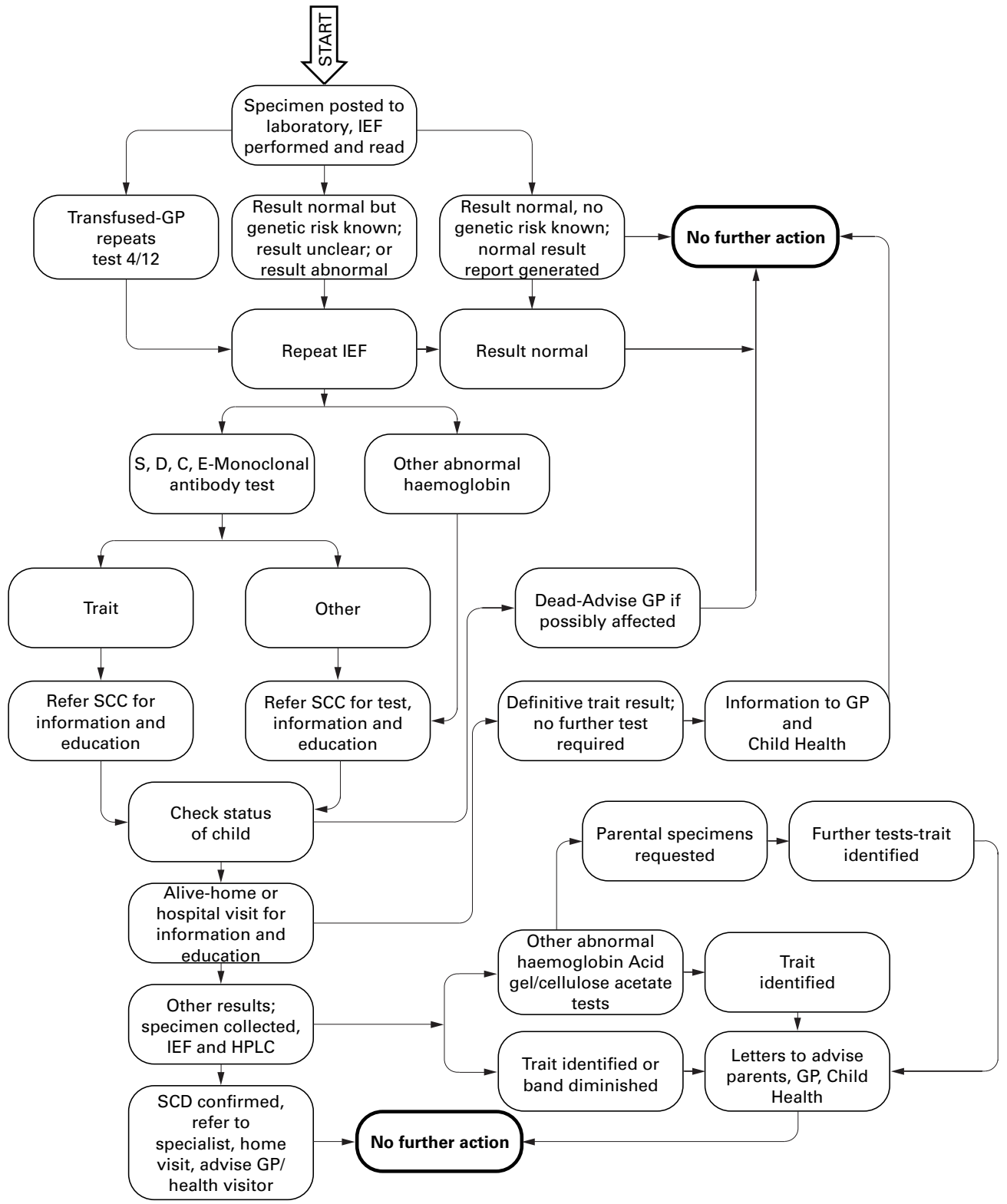

Figure 1 Overview of laboratory process for neonatal haemoglobinopathy screening.

noted that Afro-Caribbeans, Cypriots, and Italians frequently marry outside their ethnic group, so dissociating risk for haemoglobinopathies from the ethnic group to a wider population. The assumption that particular ethnic groups are not at risk for haemoglobinopathies may be less and less appropriate. This was also recognised by Horn et $a l^{15}$ and Barton and Watson, ${ }^{16}$ who suggested that intermarriage between ethnic groups in the UK would eventually necessitate universal screening.

The prime objective of neonatal haemoglobinopathy screening is to identify children with sickle cell disease (SCD), to provide advice and protection, in particular, by starting prophylactic penicillin. ${ }^{17}$ Screening will also identify sickle cell carrier babies whose families will require counselling and family studies; and an organised programme will help to raise awareness of haemoglobinopathies among health service staff and communities at risk. ${ }^{1}$
No published study, as far as we are aware, has reported the full benefits of neonatal screening for haemoglobinopathies. Economic evaluation should include the enumeration and measurement of all financial and non-financial costs and benefits of a policy, for the patient, the family, and society. ${ }^{18}$ Sprinkle and Konrad ${ }^{19}$ used one half of the price paid for finding phenylketonuria (PKU) as a measure of an acceptable price for identifying SCD, without any very clear justification. However, this is useful in drawing attention to the comparison between haemoglobinopathies and other diseases for which screening is an option. Useful comparisons can also be made with neonatal screening for congenital hypothyroidism, which affects about 25 in every 100000 . The UK adopted national, universal screening for this disease in $1981 .{ }^{20} \mathrm{PKU}$ affects 11 in every 100000 babies screened in the UK, and a universal screening policy was adopted in 1969 . 
Table 1 Programme costs common to both technologies and costs specific to isoelectric focusing (IEF)

\begin{tabular}{lrr}
\hline & $\begin{array}{c}\text { Fixed } \\
(£)\end{array}$ & \multicolumn{1}{c}{$\begin{array}{c}\text { Variable } \\
(£)\end{array}$} \\
\hline $\begin{array}{l}\text { Programme costs common to both technologies } \\
\quad \text { Processing and audit of birth } \\
\quad \text { information }\end{array}$ & \\
Reporting of normal results & 7589 & 1310 \\
Sample delivery & 0 & 736 \\
Sample registration & 0 & 856 \\
Monoclonal antibody test & 5680 & 17940 \\
Reporting of abnormal results & 0 & 4245 \\
Laboratory overheads & 0 & 2448 \\
Subtotal & 7518 & 8605 \\
IEF specific costs & 20787 & 46140 \\
Initial IEF test and immediate & & \\
$\quad$ repeats & 2392 & 53841 \\
Interpretation of results & 0 & 11285 \\
$\quad$ Repeat testing at 6 weeks & 163 & 2307 \\
Hospital overheads & 12675 & 18866.5 \\
Subtotal & 15230 & 86299.5 \\
Total & 36017 & 132439.5 \\
\hline
\end{tabular}

Table 2 Costs specific to high performance liquid chromatography (HPLC)

\begin{tabular}{lcc}
\hline HPLC specific costs & Fixed $(£)$ & $\begin{array}{l}\text { Variable } \\
(£)\end{array}$ \\
\hline $\begin{array}{l}\text { Initial HPLC test and immediate } \\
\text { repeats }\end{array}$ & 18006 & 64485 \\
$\begin{array}{l}\text { Results checking/data entry } \\
\text { Repeat testing at } 6 \text { weeks }\end{array}$ & 0 & 4323.5 \\
$\begin{array}{l}\text { Hospital overheads } \\
\text { Subtotal }\end{array}$ & 12675 & 17321.5 \\
$\begin{array}{l}\text { Total (including programme costs } \\
\text { from table 1) }\end{array}$ & 30689 & 86255 \\
& 51476 & 132395 \\
\hline
\end{tabular}

Table 3 Average costs in pounds by outcome

\begin{tabular}{lcc}
\hline Outcome costs & IEF $(£)$ & HPLC (£) \\
\hline Average cost per baby tested (47948) & 3.51 & 3.83 \\
Cost per SCD identified (25) & 6738 & 7355 \\
Cost per trait identified (721) & 234 & 255 \\
\hline
\end{tabular}

SCD, on the other hand, affects about 26 in every 100000 babies in England $^{2}$ and there is no national policy on screening.

Tsevat et $a l^{\beta}$ calculated costs per life gained solely as a result of prophylactic penicillin, but did not consider other benefits such as those of education about splenic sequestration..$^{521} 22$ or the effectiveness of early diagnosis and expectant clinical management, irrespective of penicillin prophylaxis. ${ }^{23}$ A complete assessment of benefits would consider outcomes such as the avoidance of misdiagnosis of clinical manifestations; opportunity for prophylaxis against infections; prompt treatment of manifestations; screening of siblings; genetic counselling of parents ${ }^{23}{ }^{24}$; an informed population; informed carriers; reassurance, ${ }^{2}$ and parental education about acute splenic sequestration. ${ }^{16}$ It is clear that there is further work to be done in quantifying the benefits of neonatal screening for haemoglobinopathies. This study does not attempt this, but seeks to quantify the costs. It does not directly address the question of whether screening is worthwhile, ${ }^{25}$ but is useful for comparing programmes in regions of varying prevalence, and the model described can be adapted for other screening programmes.

Components of average cost per baby tested (IEF; CMH programme)

Fixed 0.75

Population dependent 2.48 Prevalence dependent 0.28 \begin{tabular}{ll} 
Total average cost & 3.51 \\
\hline
\end{tabular}

\section{Methods}

The costing model presented identifies cost per case detected and cost per extra case detected. There are non-financial costs and costs falling outside health services in all screening programmes, such as costs and stress on the family and society caused by screening, notification, and follow up, which have not been included.

Information has been collected from the neonatal screening programme based at the haematology laboratory at Central Middlesex Hospital in north west London which screens all neonates born in the North Thames (West) region for haemoglobinopathies (around 50000 annually). The service provides full diagnosis and follow up of any haemoglobinopathies, in addition to (narrowly defined) screening. The Region has a population that is $19 \%$ non-white (for individual districts the range is $3 \%$ to $61 \%$ ). Overall, the region has a prevalence of 9.34 per 1000 sickle and cell traits combined, and 0.41 per 1000 cases of SCD.

Neonatal screening programmes are able to identify cases of thalassaemia major but not beta thalassaemia trait, so we have excluded thalassaemia from our discussion. In addition, the advantages to a child of neonatal diagnosis of SCD, or a variant haemoglobin, is of greater benefit than for thalassaemia.

Every baby born in the Region has additional drops of blood placed on a separate filter paper (Guthrie card) at the time of screening for PKU and congenital hypothyroidism. This is done by a midwife about seven days after the birth. There is no cost incurred to the haemoglobinopathy programme for initial specimen collection because this is performed as part of a general neonatal screen, which was established for PKU and hypothyroidism. Fig 1 provides an overview of the process that follows.

The Central Middlesex Hospital programme uses isoelectric focusing (IEF) to screen all samples initially, and where haemoglobin $S$ and $\mathrm{C}$ are indicated, this is confirmed by monoclonal antibody testing immediately. Follow up is undertaken by specially trained nurse counsellors. Families with babies with definitive trait results are visited in their homes and provided with information and non-directive genetic counselling. Those whose initial results indicate two or more abnormal haemoglobin genes or an unidentified band are also visited in their homes (when the infant is aged term plus 6 weeks) for counselling and the collection of a confirmatory specimen. Responsibility for further specimen collection and follow up lies with the programme. In 1994, of 26 initial results which indicated clinically significant haemoglobinopathies, only one could not be confirmed, because of parental refusal.

Follow up specimens for unidentified traits or confirmation of clinically significant disease are tested with IEF and high performance liquid chromatography (HPLC). HPLC provides an automated and quantitative analysis, whereas IEF requires visual inspection and consensus decision making to derive presumptive phenotypes, introducing the potential for human error and judgment. ${ }^{26}$ The interpretative nature of IEF means that there are greater requirements for staff and training. ${ }^{27}$ However, IEF can provide more information because of 
Table 5 Effects of prevalence and number of births on the average costs of identifying cases of sickle cell disease

\begin{tabular}{|c|c|c|c|c|c|}
\hline \multirow{2}{*}{$\begin{array}{l}\text { Disease rate (per } \\
1000 \text { births) }\end{array}$} & \multicolumn{5}{|c|}{ Effects of prevalence and number of births on cost of identifying $S C D$} \\
\hline & 5000 & 10000 & 25000 & 50000 & 100000 \\
\hline 0.01 & $1,078,160$ & 540,599 & 218,062 & 110,550 & 56,793 \\
\hline 0.02 & 540,599 & 271,818 & 110,550 & 56,793 & 29,915 \\
\hline 0.04 & 271,818 & 137,428 & 56,793 & 29,915 & 16,476 \\
\hline 0.08 & 137,428 & 70,232 & 29,915 & 16,476 & 9,757 \\
\hline 0.16 & 70,232 & 36,635 & 16,476 & 9,757 & 6,397 \\
\hline 0.31 & 37,274 & 20,475 & 10,396 & 7,036 & 5,357 \\
\hline 0.63 & 19,676 & 11,277 & 6,237 & 4,557 & 3,717 \\
\hline 1.25 & 10,477 & 6,278 & 3,758 & 2,918 & 2,498 \\
\hline 2.50 & 5,678 & 3,578 & 2,318 & 1,898 & 1,688 \\
\hline
\end{tabular}

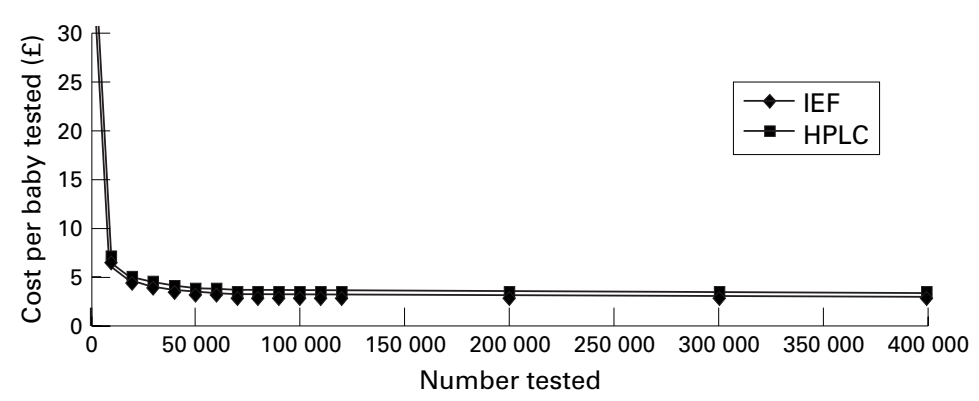

Figure 2 Comparison of the average costs per baby tested using IEF and HPLC.

its high resolution of haemoglobin variants. ${ }^{28}$ The major disadvantage of HPLC is its inability to detect some "fast-moving" variants. ${ }^{29}$

To establish the full costs of the Central Middlesex Hospital neonatal screening and diagnosis programme, we used workload figures from the 1994 calendar year (for which complete data were available) and cost data for 1994-5 and the calendar year 1995. Adjustments were made to 1994 workload information where there had been changes in screening practice. Items were costed according to time taken as a proportion of annual productive hours for the relevant staff salary and other employment costs. Costs of consumables were applied to relevant tasks, as were annual equivalent costs of capital (which were calculated using a discounted rate of $6 \%$ over seven years). Hospital overheads were calculated in terms of their fixed and variable elements. Laboratory overheads (supervision, clinical direction, training, stationery, stock control and general clerical costs) were apportioned in the same way. Medical laboratory scientific officer (MLSO) staff costs were treated as variables given interchangeability between laboratory sections. Inputs likely to remain unchanged regardless of the size of the programme-for example, supervision by MLSO 4, haematologist, stock control and laboratory clerical duties - are fixed elements of the costs. As the Central Middlesex Hospital laboratory does not use HPLC for initial testing of neonatal samples, costs for this method were identified with the assistance of St Thomas's Hospital haematology laboratory which uses the Biorad Variant analyser for its adult testing programme. Information on capital and consumable costs was provided by the manufacturer.

Average total cost per test is made up of the fixed element, and two variable elements: one being population dependent, the other prevalence dependent. A component of average cost per baby tested that is prevalence dependent was identified, because a laboratory in a region of low prevalence performs fewer repeat tests than one in a high prevalence area.

\section{Results}

The total costs, and consequently the average costs per baby tested by IEF and HPLC, are similar (tables 1 to 4 ). All are quoted in pounds

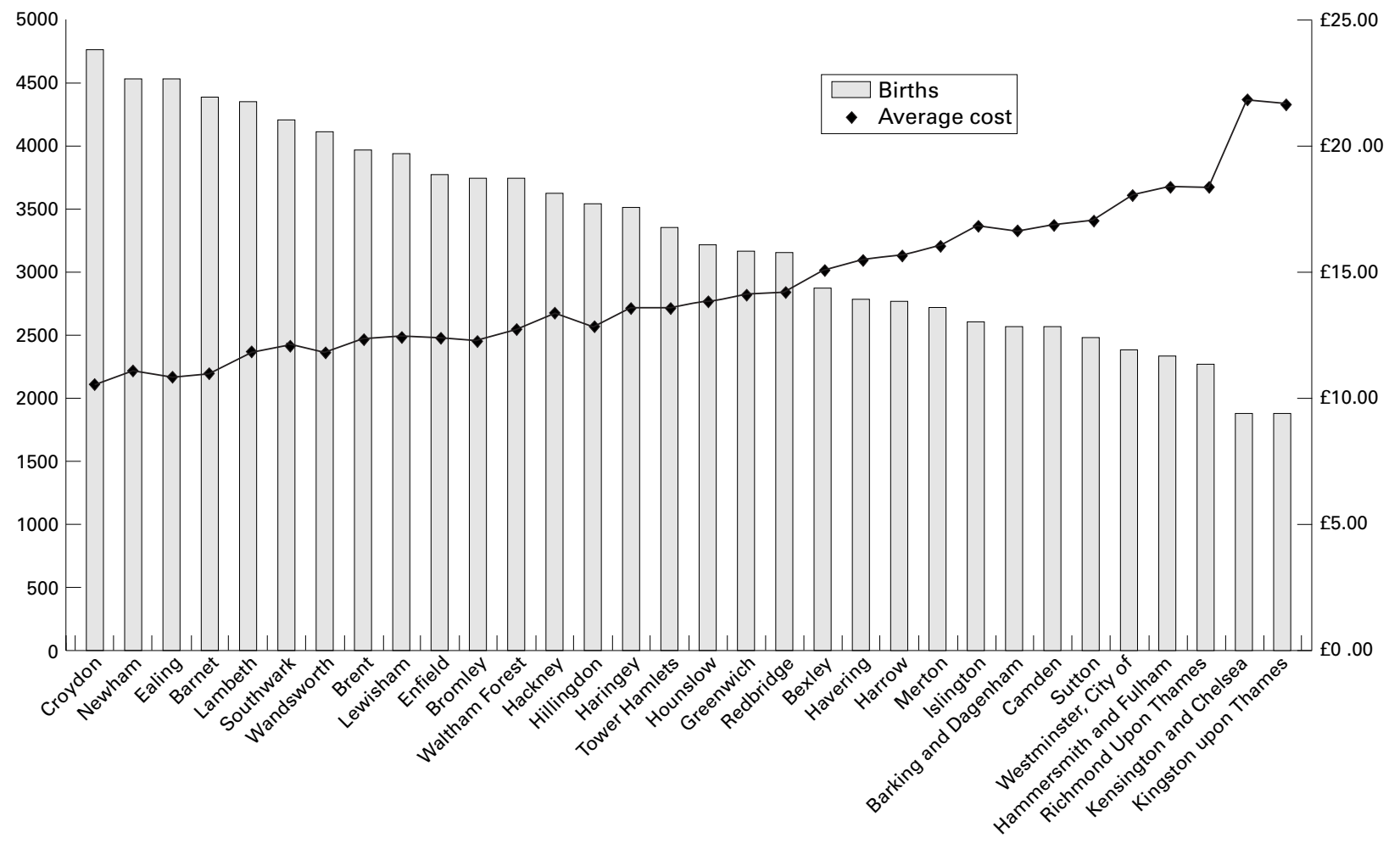

Figure 3 Average cost per baby tested by London commissioning district (IEF/HPLC). 


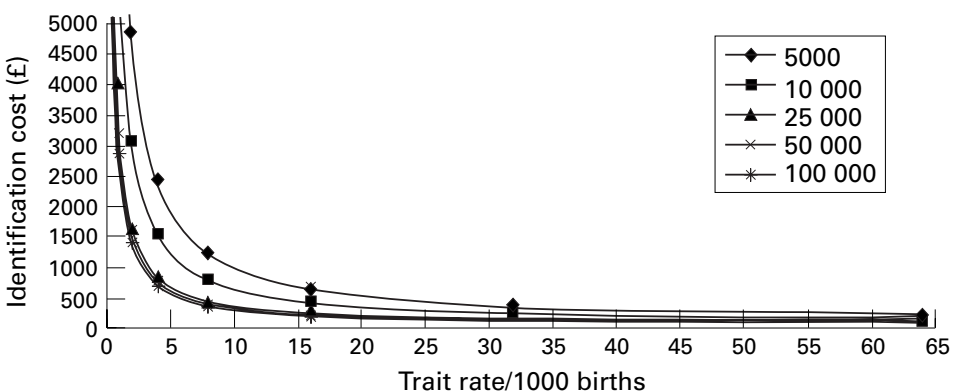

Figure 4 Effects of prevalence and annual number of births on the cost of identifying traits in a universal programme using IEF.

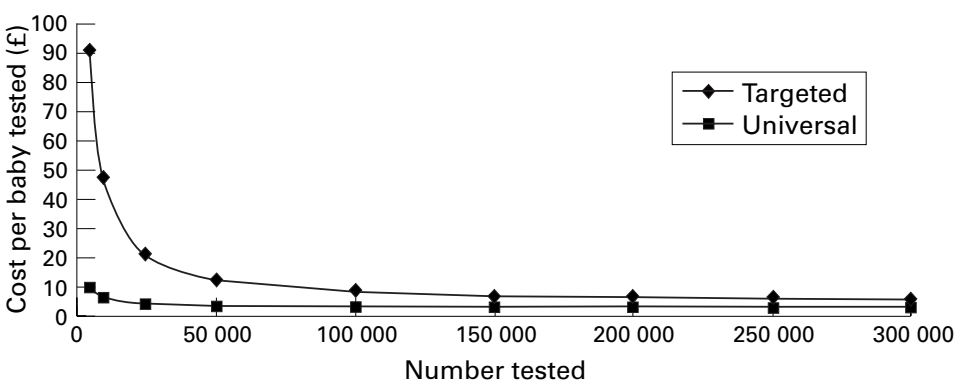

Figure 5 Comparison of average costs per baby tested using IEF in universal and targeted programmes.

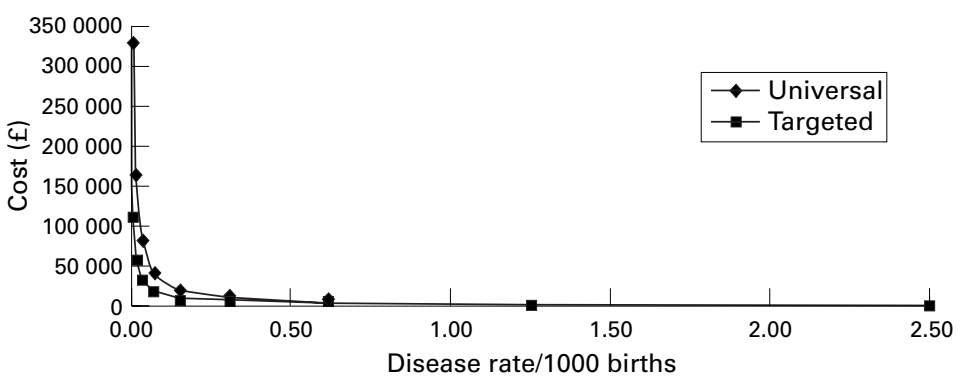

Figure 6 Comparison of identification costs for cases of sickle cell disease, using IEF in universal and targeted programmes of 50000 births annually.

sterling at 1994-5 prices for the Central Middlesex Hospital programme which covers around 50000 neonates. The average costs of identifying cases of sickle cell disease are shown in table 5 .

The variable costs for a programme which screened 47948 babies amounted to $£ 132439$ for IEF and $£ 132395$ for HPLC, although these are made up of different components. Consumables (reagent kits and small replacements) for IEF came to $£ 34630$, while the equivalent for HPLC is $£ 59$ 911. Staff costs for the IEF test were $£ 27320$ and costs for the initial HPLC test, $£ 9156$. This shows that, if the consumable costs for HPLC fall, the total costs of screening would be lower using HPLC.

AVERAGE COSTS PER BABY TESTED

Fig 2 shows average costs. There are economies of scale up to a programme size of 25000 . The data also show little difference between IEF and HPLC in terms of average cost per baby tested. The bumps on the graph reflect the annual equivalent cost (AEC) of a new HPLC analyser at intervals of 25000 tests. The cost of additional IEF equipment occurs at every 100000 tests.
Fig 3 provides information about average cost per baby tested across London districts, clearly showing the correlation between number of births and average cost.

COSTS OF IDENTIFYING SCD AND TRAIT

Table 4 shows how the average costs of identifying a case of SCD, using IEF, depend both on changes in disease prevalence and the number of births screened. Once the number of births reaches 25000 , it seems to make very little difference to the identification cost. These rise sharply below a disease rate of $0.5 / 1000$ and a trait rate of below 15/1000. The technology used makes little difference. Fig 4 gives similar information for identifying a baby with a trait. These data can be used to model costs for programmes where the gene frequency in the population is either known or has been calculated from census data. ${ }^{7}$

TARGETED PROGRAMME COSTS

A disease rate of $0.5 / 1000$ is relatively high in England, with half the districts having a prevalence of lower than $0.04 / 1000$ and only $10 \%$ (unadjusted for population size) showing a prevalence of greater than $0.3 / 1000$.

Cost modelling of targeted screening assumed that targeting would overestimate the size of the at risk population by $20 \%$, but nevertheless fails to test $20 \%$ of at risk babies (based on evidence from Georgia in the USA, although in Colorado (Abstract presented to Ninth National Neonatal Screening Symposium, Raleigh, NC, 1992), risk group misclassification has been estimated at $30 \%$ ).

Responsibility for selection of those babies at risk for haemoglobinopathies is likely to lie with the midwife and is associated with extra costs. For the purpose of costing, taking a family history has been estimated to take an average of five minutes. Most neonatal laboratory screening programmes cover PKU and congenital hypothyroidism. To exclude (and then retrieve and refile) non-selected cards from haemoglobinopathy testing would incur additional clerical costs, and these have been estimated to be an additional three hours per day $(£ 5980$ per year) for the Central Middlesex Hospital programme, based on local information and evidence from Colorado (Abstract presented to Ninth National Neonatal Screening Symposium, USA, 1992).

The difference in average cost per baby tested in targeted and universal programmes is shown in fig 5 for IEF. Targeted programmes for both IEF and HPLC have higher average costs per baby tested than universal programmes.

COMPARISON OF UNIVERSAL AND TARGETED PROGRAMMES

As the fixed costs are quite high, the costs of SCD and trait identification for universal and targeted screening in small programmes are very similar. At 5000 births and at low prevalence, identification costs are slightly lower for universal screening. At high prevalence, regardless of the number of births, identification costs are very similar. At low 
Table 6 Costs per extra case of sickle cell disease in a universal programme using IEF or HPLC

\begin{tabular}{|c|c|c|c|c|c|}
\hline \multirow{2}{*}{$\begin{array}{l}\text { Disease rate (per } 1000 \\
\text { births) }\end{array}$} & \multicolumn{5}{|c|}{ Cost per extra SCD identified by universal programme (number of births) } \\
\hline & 5000 & 10000 & 25000 & 50000 & 100000 \\
\hline \multicolumn{6}{|l|}{ IEF } \\
\hline 0.01 & 647981 & 954157 & 1137862 & 1199098 & 1229715 \\
\hline 0.02 & 316114 & 472202 & 564055 & 594673 & 609981 \\
\hline 0.04 & 154681 & 231225 & 277151 & 292460 & 300114 \\
\hline 0.08 & 72464 & 110736 & 133699 & 141354 & 145181 \\
\hline 0.16 & 31356 & 50492 & 61973 & 65801 & 67714 \\
\hline 0.31 & 8244 & 17812 & 23553 & 25466 & 26423 \\
\hline 0.63 & 1164 & 5948 & 8819 & 9775 & 10254 \\
\hline 1.25 & -777 & 1615 & 3050 & 3529 & 3768 \\
\hline 2.50 & -948 & 248 & 965 & 1205 & 1324 \\
\hline \multicolumn{6}{|l|}{ HPLC } \\
\hline 0.01 & 702708 & 1008884 & 1192590 & 1253825 & 1284442 \\
\hline 0.02 & 346219 & 4993072 & 591160 & 621778 & 637087 \\
\hline 0.04 & 167975 & 244519 & 290445 & 305754 & 313409 \\
\hline 0.08 & 78853 & 117125 & 140088 & 147743 & 151570 \\
\hline 0.16 & 34292 & 53428 & 64909 & 68737 & 70650 \\
\hline 0.31 & 9371 & 18939 & 24679 & 26593 & 27550 \\
\hline 0.63 & 1531 & 6315 & 9186 & 10142 & 10621 \\
\hline 1.25 & -738 & 1654 & 3086 & 3568 & 3807 \\
\hline 2.50 & -1047 & 149 & 866 & 1106 & 1225 \\
\hline
\end{tabular}

Table 7 Sensitivity analysis

\begin{tabular}{|c|c|c|}
\hline & Assumption/varied to & $\begin{array}{l}\text { Amount of } \\
\text { difference }\end{array}$ \\
\hline a & $\begin{array}{l}\text { Targeted programmes will miss } 20 \% \text { of SCDs targeted programmes will } \\
\text { miss } 10 \% \text { of SCDs }\end{array}$ & Significant \\
\hline $\mathrm{b}$ & $\begin{array}{l}\text { Targeted programmes will miss } 20 \% \text { of SCDs targeted programmes will } \\
\text { miss } 1 \% \text { of SCDs }\end{array}$ & Significant \\
\hline c & Hospital overheads as modelled hospital overheads doubled & $\begin{array}{l}\text { Not significant } \\
\text { in populations } \\
>25000\end{array}$ \\
\hline $\mathrm{d}$ & Current cost of HPLC reagents cost of HPLC reagents halved & Significant \\
\hline $\mathrm{e}$ & SCD births according to prevalence (no PND/TOP)/TOP in $20 \%$ & Significant \\
\hline $\mathrm{f}$ & SCD births according to prevalence (no PND/TOP)/TOP in $10 \%$ & Not significant \\
\hline $\mathrm{g}$ & $\begin{array}{l}\text { Midwife selection will take } 5 \text { minutes midwife selection will take } 10 \\
\text { minutes }\end{array}$ & Not significant \\
\hline $\mathrm{h}$ & Midwife selection will take 5 minutes midwife selection will take 2 minutes & Not significant \\
\hline $\mathrm{i}$ & $\begin{array}{l}\text { Targeted programmes will incur extra clerical costs targeted programmes } \\
\text { will not incur extra clerical costs }\end{array}$ & $\begin{array}{l}\text { Not significant } \\
\text { in populations } \\
>25000\end{array}$ \\
\hline j & $\begin{array}{l}\text { Fixed costs as modelled fixed costs plus } 20 \% \text { and corresponding decrease } \\
\text { in variable costs }\end{array}$ & Not significant \\
\hline $\mathrm{k}$ & CMH hospitals overheads hospital overheads halved & Not significant \\
\hline 1 & $\begin{array}{l}\text { Targeted programmes will overestimate at-risk population by } 20 \% \text { targeted } \\
\text { programmes will overestimate at-risk population by } 40 \%\end{array}$ & Not significant \\
\hline $\mathrm{m}$ & $\begin{array}{l}\text { Targeted programmes will overestimate at risk population by } 20 \% \text { targeted } \\
\text { programmes will accurately estimate at-risk population }\end{array}$ & Not significant \\
\hline
\end{tabular}

prevalence and 25000 or more births, the identification costs of SCD and trait are consistently higher with universal programmes (fig 6).

We have modelled the failure rate of targeted programmes to pick up all cases of SCD, at $20 \%$, and, subsequently, calculated the cost of each extra SCD identified by a universal programme (compared with a targeted programme).

The key issue for purchasing organisations is the incremental cost effectiveness of identifying one extra case of SCD with a universal programme. Table 6 shows cost per extra SCD identified by a universal programme compared with a targeted programme. Commissioners will need to consider whether, for their population and prevalence, they are willing to spend the given amount to pick up one case of SCD.

SENSITIVITY ANALYSIS

Sensitivity testing of key assumptions has been performed using "cost per extra SCD identified by universal programme" as an indicator. Table 7 provides a summary of the assumptions varied and the responding sensitivity of the indicator. We have assumed that assumptions are accurate within a range of $20 \%$. The sensitivity analysis, therefore, concludes that indicators must vary beyond $20 \%$ of the baseline to demonstrate sensitivity to that assumption.

\section{Discussion}

Given significant economies of scale up to 25000 births per year (and further up to 40000 to 50000 ), the organisation of screening services should aim to cover a screened population which will generate this level of work. Districts with lower numbers of babies to be screened should collaborate to achieve scale economies.

IEF and HPLC are very similar in terms of average cost per test and the choice of method should depend mainly on the level of expertise and staff mix of the laboratory. If the price of consumables comes down, HPLC will become cheaper than IEF, and a choice of IEF would depend on the need for the additional information generated.

The decision whether to use a universal or targeted strategy should not be based on ethnicity, but on the number of births, the prevalence and resulting cost per extra SCD identified with universal screening. The SMAC report ${ }^{1}$ cites $15 \%$ ethnicity as the point at which universal screening should be introduced. Universal programmes will probably be considered good value at a disease prevalence of 0.1 or 0.3 per 1000 births, where the cost of an additional case detected is in the range 25000 to 100000 . This is likely to be below the figure suggested by the SMAC report, but would apply to areas such as North Thames (West).

At 16 traits $/ 1000$ and $0.5 \mathrm{SCD} / 1000$ there is no significant identification cost difference between universal and targeted programmes. Below this prevalence a targeted programme is cheaper, but is likely to miss cases of SCD. The potential for litigation and settlement costs associated with missed cases should not be overlooked.

The sensitivity analysis illustrates that if targeted programmes were $90-99 \%$ effective, universal programmes would cease to be good value except at very high prevalence. If hospital overheads double, targeted programmes become more cost effective. Greater use of prenatal diagnosis, resulting in termination, and therefore fewer affected births, reduces the cost effectiveness of universal screening.

The benefits of neonatal screening, as with all screening programmes, depend on there being an intervention that is more effective when started early, and the availability of this intervention. A screening programme with follow up counselling and access to early treatment is, therefore, likely to realise the maximum potential benefits. Some screening programmes, for example, some in the USA, have more limited follow up, and this may limit their effectiveness and cost effectiveness.

Our thanks to all the staff of the Brent Sickle Cell and Thalassaemia Centre who provide the counselling service.

We acknowledge funding from the NHS Health Technology Assessment Programme; grant 93/33/3. 
1 Department of Health. Report of a Working Party of the Standing Medical Advisory Committee on Sickle Cell, Thalassaemia, 1993.

2 Hickman M, Modell B, Greengross P, Chapman C, Layton M, Falconer S, Davies SC. Mapping the prevalence of sickle cell and $\beta$ thalassaemia in England: recommended rates for local service planning. (In press)

3 Tsevat J, Wong JB, Pauker SG, Steinberg MH. Neonatal screening for sickle cell disease: A cost-effectiveness analysis. 7 Pediatr 1991;118:546-54

4 Lane PA, Eckman JR. Cost effectiveness of neonatal screening for sickle cell disease. F Pediatr 1992;120:142-3.

5 Wright F. London after Tomlinson: Haemoglobinopathy Services in Kensington, Chelsea and Westminster. British Society of Haematology, London: 1993.

6 Sprinkle RH, Hynes DM, Konrad TR. Is universal neonatal hemoglobinopathy screening cost-effective? Arch Pediatr Adolesc Med 1994; 148:461-9

7 US Department of Health \& Human Services. Sickle Cell Disease: Screening, diagnosis, management, and counselling in newborns and infants:

8 Modell B, Anionwu EN. Guidelines for screening for haemoglobin disorders: service specifications for low and high prevalence DHAs. In: NHS Centre for Reviews and Dissemination/Social Policy Research Unit. Ethnicity and Health: Reviews of literature and Guidance for Purchasers in
the Areas of Cardiovascular Disease, Mental Health, and Haemoglobinopathies. CRD Report 5, 1995:127-224.

9 Githens JH, Lane PA, McCurdy RS, Houston ML, McKinna JD, Cole DM. Newborn screening for hemoglobinopathies in Colorado. Am f Dis Child 1990;144:46670.

10 Hurst, D. Northern California's experience. Pediatrics 1989;83 (Supplement):868-71.

11 Harris M, Eckman JR. Georgia's experience with newborn screening: 1981-1985. Pediatrics 1989;83(Supplement): 858-60.

12 Griffiths P, Mann JR, Darbyshire PJ, Green A. Evaluation of eight and a half years of neonatal screening for 1583-5.

13 Consensus Conference. Newborn screening for sickle cell disease and other haemoglobinopathies. $\mathcal{F} A M A$ 1987;258:1205-9.
14 Adjaye N, Bain BJ, Steer P. Prediction and diagnosis of sickling disorders in neonates. Arch Dis Child 1989;64:39-43.

15 Horn M, Dick M, Frost B, et al. Neonatal screening for sickle cell diseases in Camberwell: results and recommendations of a two year pilot study. BMF 1986;292:737-40.

16 Barton C, Watson A. Neonatal screening for haemoglobinopathies. BMF 1988;297:200

17 Gaston MH, Verter JI, Woods G, et al. Prophylaxis with oral penicillin in children with sickle cell anemia. N Engl f Med 1986;314:1593-9.

18 Drummond MF. Principles of economic appraisal in health care. Oxford: Oxford University Press, 1980

19 Sprinkle RH, Konrad TR. Is universal neonatal hemoglobinopathy screening cost-effective? Arch Pediatr Adolesc Med 1995;149:466-7.

20 Holland W, Stewart S. Screening in Health Care: Benefit or Bane? Oxford: Nuffield Provincial Hospitals Trust, 1990.

21 Emond AM, Collis R, Darvill D, Higgs DR, Maude GH, Serjeant GR. Acute splenic sequestration in homozygous sickle cell disease: natural history and management. 7 Pediatr 1985;107:201-6.

22 Lee A, Thomas P, Cupidore L, Serjeant B, Serjeant G. Improved survival in homozygous sickle cell disease: lessons from a cohort study. BMF 1995;311:1600-2.

23 Rowley P, Huntzinger D. Newborn sickle cell screening. Am f Dis Child 1983;137:341-5.

24 Kinney T, Sawtschenko M, et al. Techniques' comparison and report of the North Carolina experience. Pediatrics 1989;83(Supplement):843-8.

25 Cairns J, Shackley P. Tries hard but could do better: a report on the economics of screening. Aberdeen: Health Economics the economics of screening. Aberdee
and Research Unit, London, 1992.

26 Eastman JW, Wong R, Liao CL, Morales DR. Automated HPLC screening of newborns for sickle cell anemia and other hemoglobins. Clin Chem 1996;42:704-10.

27 Delahunty T. Convenient screening for hemoglobin variants by using the Diamat HPLC system. Clin Chem 1990;36:903-5.

28 Kleman KM, Vichinsky E, Lubin BH. Experience with newborn screening using isoelectric focusing. Pediatrics newborn screening using isoe

29 Huisman T. Usefulness of cation exchange high performance liquid chromatography as a testing procedure. Pediatrics 1989;83(Supplement):849-51. 